Research Article

\title{
Stability Analysis of Ecological Slopes Based on a 3D Finite Element Model
}

\author{
ZiFan Sui, ${ }^{1}$ Weijia Yuan, ${ }^{1}$ Wen $Y i D^{D},{ }^{1}$ and Weihuan Yang ${ }^{2}$ \\ ${ }^{1}$ Central South University of Forestry \& Technology, Changsha, Hunan 410004, China \\ ${ }^{2}$ Zhejiang Runcheng Environmental Protection Group Co.,Ltd., Hangzhou, Zhejiang 311500, China \\ Correspondence should be addressed to Wen Yi; yiwengangbiao@163.com
}

Received 19 August 2021; Revised 7 October 2021; Accepted 13 October 2021; Published 5 November 2021

Academic Editor: Qiao Dong

Copyright (c) $2021 \mathrm{ZiFan}$ Sui et al. This is an open access article distributed under the Creative Commons Attribution License, which permits unrestricted use, distribution, and reproduction in any medium, provided the original work is properly cited.

To explore the effect of grass and shrub plant roots on the stability of soil slopes in rainy areas in the south, this article relies on the Longlang Expressway construction project. Cynodon dactylon and Magnolia multiflora were selected as research subjects. The plant distribution characteristics and mechanical properties are analyzed. This paper uses ABAQUS finite element software to construct a 3D model of the planted slope in the test section. The stress and strain on the root system and the soil were observed, and the variation law of slope stability before and after plant protection under different rainfall events was compared and analyzed. The test and simulation results show that the root content of Cynodon dactylon gradually decreases with increasing depth. Cynodon dactylon was mainly distributed in the $0-30 \mathrm{~cm}$ soil body, and its effect on improving the cohesion of the soil body reached $75 \%$. Magnolia multiflora belongs to vertical roots and has a strong and longer main root with relatively developed lateral roots. Its root system passes through the sliding surface of the slope bottom, which reduces the maximum equivalent plastic stress generated inside the slope by $61 \%$. When the total rainfall duration is unchanged, under the three rainfall intensities of small, medium, and large, herbaceous plants increase the safety factor of the soil by $1.33 \%, 2.08 \%$, and $6.1 \%$, respectively, and the roots of shrubs increase the safety factor of the soil by $3.29 \%, 4.08 \%$, and $4.32 \%$, respectively. When the rainfall intensity does not change, as the rainfall time increases, the effect of plants on the slope safety factor first gradually increases and eventually stabilizes. The research results provide a reliable theoretical basis for analyzing the effect of plant roots on soil consolidation and slope protection, and they also lay a technical foundation for the promotion and application of ecological slope protection technology.

\section{Introduction}

Soil erosion is one of the world's major environmental disasters, and China is also the country with the most serious soil erosion and the most threatened level in the world $[1,2]$. During road construction, especially when excavating the soil in mountainous areas, a large amount of secondary bare land will be produced, and the original vegetation cover will be disturbed and changed, often causing serious water and soil erosion problems [3-5]. The proposal of ecological slope protection technology has made a great contribution to the improvement of this problem [6]. Plants rely on the hydrological effects of their stems and leaves and the mechanical effects of the root system to ensure a stable slope while also achieving the purpose of preventing soil erosion, saving project costs, and beautifying road landscapes [7, 8]. It is an environmentally friendly slope protection method that has been widely used in highway slope protection projects [9].

The role of plants on slopes has advantages and disadvantages. Some scholars have pointed out that the weight of plants will cause the slope to bear greater vertical pressure. Under the action of wind load, the root system has a tendency to be pulled out, and the slope is more prone to instability and damage $[10,11]$. However, more scholars believe that plants can have a reinforcing effect on slopes. Plant stems and leaves reduce the erosion and splash erosion of the soil on the slope surface by rain and effectively inhibit the generation of runoff; at the same time, the dense root system in the soil is interwoven into a network, which 
significantly improves the strength of the soil $[12,13]$. To further explore the influence of roots on slopes, scholars have carried out direct shear, triaxial, and unconfined compressive tests by observing changes in the shear strength of root-soil complexes and quantitatively analyzed the strengthening effects of plant roots on the soil [14-17]. There are also some studies that estimate the influence of roots on the soil by constructing theoretical models between roots and soils, such as the $\mathrm{Wu}$ model, Waldron model, and FBM model [18-20].

However, the relationship between plant roots and soil is more complicated, there are many factors that affect the process of experimental and theoretical analysis, and the results cannot intuitively reflect the changing laws of slope stability before and after planting [21, 22]. With the improvement of computer performance, many scholars have begun to use finite element software to analyze actual engineering problems. By constructing a $1 \mathrm{D}, 2 \mathrm{D}$, or $3 \mathrm{D}$ model of the slope and observing the plastic zone and the stress and strain, the safety factor of the slope can be easily solved and the stability of the slope can be analyzed [23-25]. In recent years, many studies have also begun to use numerical simulation methods to analyze root-soil coupling problems. In the modeling process, the construction of plant root units and the choice of root-soil contact types will determine the calculation accuracy of the model [26]. There are mainly four modeling methods that are widely used at present: (1) regardless of the morphology of the plant root system, the plant and soil are regarded as composite materials, and attributes are given as a whole; (2) the interaction between the plant and the soil is converted into a load, which is directly applied to the soil element; (3) the soil and root models are built separately, assuming that the deformation between the two can be automatically coordinated; (4) while separating the root system of the plant and the soil, the relative movement of the two is restricted by setting the contact method between the two [27-30].

Plants are biological materials, and their mechanical properties are closely related to factors such as root morphology and soil moisture content. In previous studies, this was often simplified, resulting in large errors in the simulation results $[17,31]$. In this paper, based on the geological and hydrological conditions of the test area and the distribution characteristics of plants on the slope, ABAQUS finite element software is used to construct $3 \mathrm{D}$ models of shallow grass, deep shrub roots, and soil slopes, and the strength reduction method is used to analyze the influence of plant roots on slope stability during rainfall. This research has important theoretical guiding significance for preventing and controlling the occurrence of slope geological disasters in rainy areas in the south and has laid a technical foundation for the promotion and application of ecological slope protection technology.

\section{Materials and Methods}

2.1. Introduction of the Study Area. The study area is located in Section $\mathrm{K} 72+123-\mathrm{K} 72+321$ of the Longlang Expressway, Xinhua County, Loudi City, Hunan Province, with a length of $198 \mathrm{~m}$ and a maximum slope height of $30.6 \mathrm{~m}$. This area is located between $111^{\circ} 15^{\prime} 10^{\prime \prime}$ and $112^{\circ} 9^{\prime} 6^{\prime \prime}$ east longitude and between $27^{\circ} 25^{\prime} 33^{\prime \prime}$ and $28^{\circ} 48^{\prime} 27^{\prime \prime}$ north latitude. It has a midsubtropical monsoon humid climate. The measured average monthly rainfall over the years is shown in Figure 1. The rainfall is mainly concentrated in April to July. The annual average temperature is $16.5^{\circ} \mathrm{C}-17.5^{\circ} \mathrm{C}$, the extreme maximum temperature is $40.1^{\circ} \mathrm{C}$, the extreme minimum temperature is $-12.1^{\circ} \mathrm{C}$, the annual average wind speed is $1.5-2.2 \mathrm{~m} / \mathrm{s}$, and the maximum wind speed is $40 \mathrm{~m} / \mathrm{s}$. The previously mentioned climatic conditions will play a decisive role in the formulation of ecological slope protection schemes, such as plant species, planting density, and construction season.

Combining the survey results and construction design, it can be seen that the main stratum of the slope of the test section is limestone and marl, which are basically soft rock. There are a small number of weak interlayers in the bedding slope rock layer, and the overall stability is good. However, surface water and groundwater are developed in the rainy season, and the stability of the shallow overburden and joint fissures is poor. If the construction stage is not handled properly, shallow slope instability and block loss are likely to occur locally. To stabilize the slope, relevant measures have been taken at the construction site, comprehensively considering the effects of the local landscape and using ecological slope protection technology to reinforce the soil. The engineering effects before and after protection are shown in Figure 2.

2.2. Material Parameters. The soil on the slope was selected as the soil for this test, the soil sample was dried, $3000 \mathrm{~g}$ was weighed for the particle screening test, and the particle grading curve and uneven coefficient were obtained. The particle composition of the soil is shown in Table 1 . In the test, 15-30 g of soil samples was taken from representative locations. The soil was weighed and dried in an oven at $105-110^{\circ} \mathrm{C}$ to a constant weight. The samples were removed and cooled and weighed again to determine the natural moisture content of the soil. The dry density of the soil was measured by sampling on the soil slope with a ring knife. The liquid limit and plastic limit of the soil were measured by a photoelectric liquid limit and plastic limit combined tester (the cone mass was $100 \mathrm{~g}$ ). The basic parameters of soil samples measured through the previously mentioned tests are shown in Table 2.

Taking into account the effect of slope protection and local geological and hydrological conditions, the four-yeargrowing herb Cynodon dactylon and the shrub Magnolia multiflora roots were selected as the research objects.

There are many kinds of herbaceous plants, the shallow soil has a large root-containing rate, and the root system mainly has a reinforcing effect [32]. The root-soil composite sample was obtained by ring knife sampling, and its root content and shear strength were determined. When sampling on-site, one can first take a large piece of soil, bring it back to the laboratory, and use a sharp knife to remove the excess part. When cutting the excess root system and 


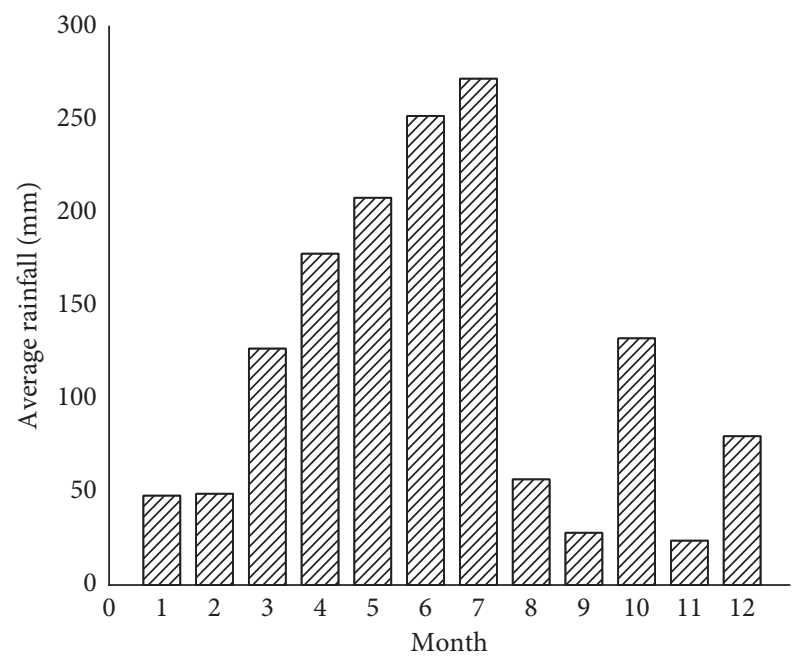

Figure 1: The average rainfall of the Longlang Expressway from 2015 to 2019.

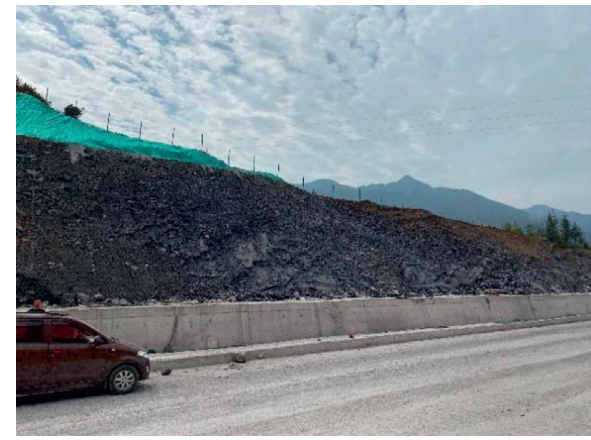

(a)

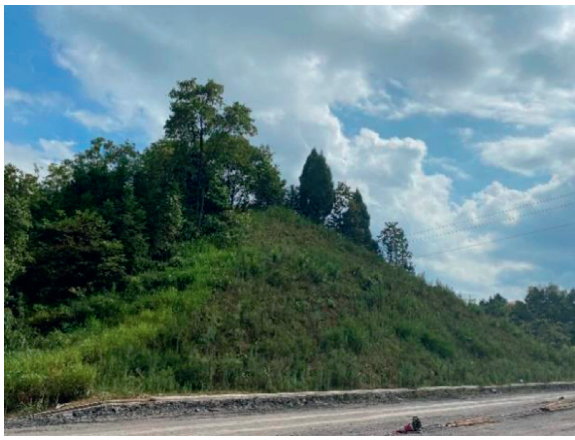

(b)

Figure 2: Landscape of the studied slope: (a) before slope protection; (b) after planting plants.

TABLE 1: Results of the sieving analysis test [26].

\begin{tabular}{lccc}
\hline Sieve diameter $(\mathrm{mm})$ & Percentage $(\%)$ & Sieve diameter $(\mathrm{mm})$ & Percentage $(\%)$ \\
\hline 40 & 0 & 1 & 11.8 \\
20 & 5.0 & 0.5 & 15.3 \\
10 & 14.2 & 0.25 & 5.7 \\
5 & 17.8 & 0.075 & 1.5 \\
2 & 28.3 & $<0.075$ & 0.3 \\
\hline
\end{tabular}

TABLE 2: Basic parameters of the soil sample.

\begin{tabular}{lcccc}
\hline Optimal moisture content (\%) & Maximum dry density $\left(\mathrm{g} / \mathrm{cm}^{3}\right)$ & Liquid limit $(\%)$ & Plastic limit $(\%)$ & Plasticity index \\
\hline 18.62 & 1.82 & 48.5 & 25.6 & 22.9 \\
\hline
\end{tabular}

surrounding soil, care should be taken not to disturb the soil sample in the ring knife. The prepared test block should be wrapped in plastic wrap and left for 5-7 days to reduce the loss of water content between the soil samples. The sample after shearing was retrieved on-site, as shown in Figure 3. The analysis shows that the herbaceous plants are mainly distributed in the $0-30 \mathrm{~cm}$ soil, and the root content decreases with increasing depth. The content of Cynodon dactylon roots in soil is shown in Figure 4. Twelve samples are taken for indoor direct shear test at three depths of $0-10 \mathrm{~cm}, 10-20 \mathrm{~cm}$ and $20-30 \mathrm{~cm}$. Coulomb formula can be used to solve parameters such as cohesion and friction angle. The soil and root composite material parameters measured through indoor tests are shown in Table 3. The root system improves the shear strength and permeability of the soil.

The root system of shrubs in the soil is not large, but the root system is deep in the soil and mainly serves as an anchor [33]. The whole plant excavation method was 


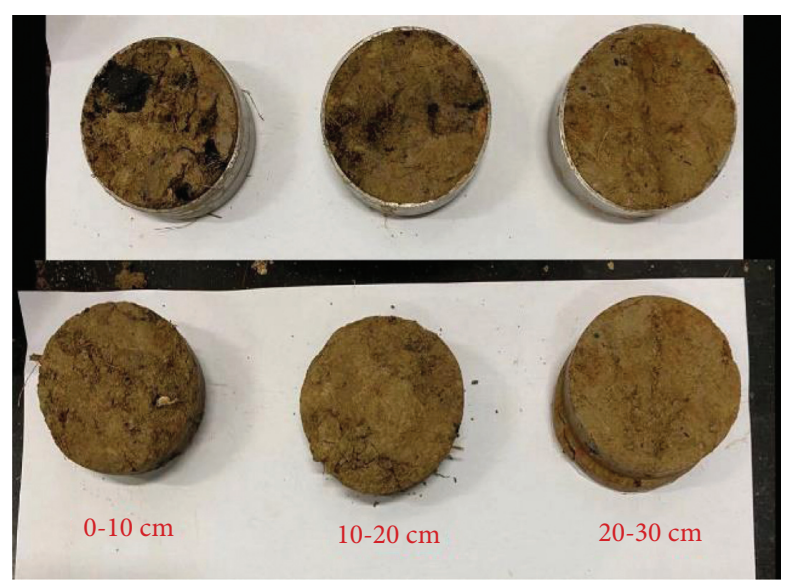

FIgURE 3: Root-soil composite sample after the direct shear test.

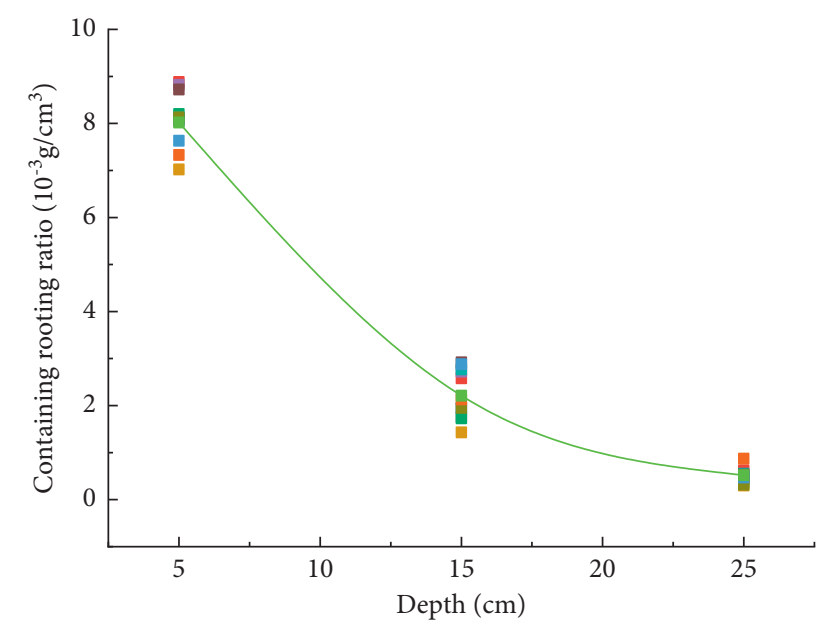

FIGURE 4: Root content change curve with depth (each point in the figure is test data, and the curve is an average value).

TABLe 3: Physical and mechanical parameters of soil materials.

\begin{tabular}{|c|c|c|c|c|c|c|}
\hline Category & $\begin{array}{l}\text { Unit weight } \\
\left(\mathrm{kN} / \mathrm{m}^{3}\right)\end{array}$ & $\begin{array}{l}\text { Elastic modulus } \\
\qquad(\mathrm{MPa})\end{array}$ & Cohesion $(\mathrm{kPa})$ & $\begin{array}{l}\text { Internal } \\
\text { friction } \\
\text { angle }\left(^{\circ}\right)\end{array}$ & $\begin{array}{l}\text { Poisson's } \\
\text { ratio }\end{array}$ & $\begin{array}{l}\text { Saturated permeability coefficient } \\
\qquad\left(10^{-4} \mathrm{~cm} / \mathrm{s}\right)\end{array}$ \\
\hline Soil & 18.75 & 10 & 29.78 & 10.31 & 0.35 & 1.02 \\
\hline $\begin{array}{l}\text { Root-soil } \\
\text { composite }\end{array}$ & 18.75 & 3.9 & 52.02 & 10.68 & 0.30 & 5.32 \\
\hline
\end{tabular}

adopted to collect all the multiple magnolias on the test slope, and the remaining 50 plants after removing the incomplete roots were classified according to the morphological characteristics of primary and lateral roots, and the root morphology was scanned and analyzed. Care should be taken to ensure the integrity of the root system during collection; the excavated root system should be covered with wet soil, and water should be regularly added to maintain it until the end of the test. Typical root morphology is shown in Figure 5. Magnolia multiflora belongs to vertical roots, with obviously thicker and longer tap roots, and some lateral roots are also more developed. The mechanical parameters determined by laboratory tests are shown in Table 4.
2.3. Model Construction. By taking the slope of the Longlang Expressway in Loudi City, Hunan Province, as the supporting project, the $3 \mathrm{D}$ model of the soil slope and plant root system is constructed by ABAQUS finite element software. The slope model has a height of $6 \mathrm{~m}$, a length of $9 \mathrm{~m}$, a width of $6 \mathrm{~m}$, a subgrade height of $4 \mathrm{~m}$, and a slope of $1: 1.5$. Taking into account the range of influence of the numerical simulation calculation, the top and toe of the slope are extended $6 \mathrm{~m}$ in each direction.

The main distribution depth of the herbaceous bermudagrass is $0-30 \mathrm{~cm}$, the root system is finer, and the root content is larger. When modeling, the plant and soil are regarded as root-soil composite materials. The unit type is the same as that of the soil, and C3D8 units are used. 

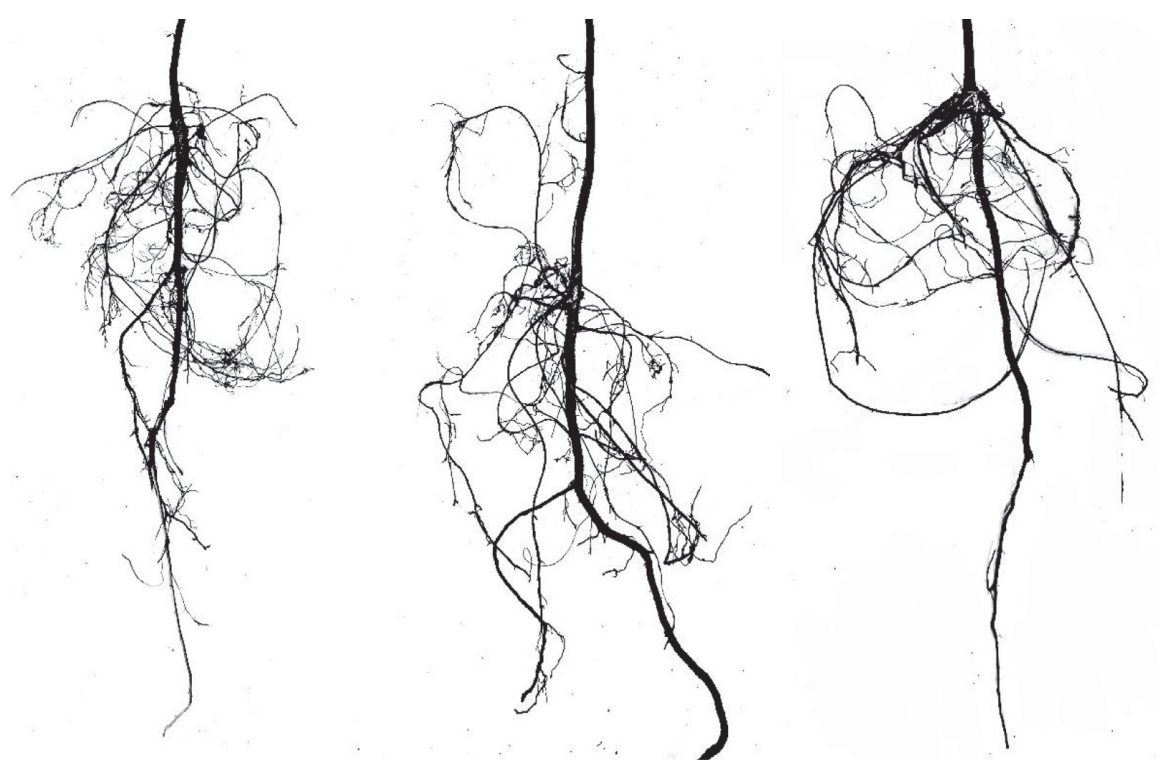

FiguRE 5: Schematic diagram of characteristic root scanning of Magnolia multiflora.

TABle 4: Physical and mechanical parameters of the root of Magnolia multiflora.

\begin{tabular}{lccc}
\hline Material & Elastic modulus $(\mathrm{GPa})$ & Poisson's ratio & Density $\left(\mathrm{kN} / \mathrm{m}^{3}\right)$ \\
\hline Root of Magnolia multiflora & 0.5 & 0.35 & 13 \\
\hline
\end{tabular}

Compared with herbs, there are far fewer shrubs on the slope. According to statistics, there is a root system of $2-3 \mathrm{~m}$ per $2 \mathrm{~m}^{2}$, which is mainly used for anchoring; therefore, it is not suitable to use composite material models. According to the scan results of the characteristic roots of shrubs, after the main roots are retained and the finer lateral roots are removed, we use the T3D2 unit to construct a properly simplified root model of Magnolia multiflora. The main roots are distributed vertically downwards, with a length of $3 \mathrm{~m}$ and a diameter of $0.1 \mathrm{~m}$, there are 5 lateral roots on each side, the inclination of the root system is $60^{\circ}$, the length of the root system from top to bottom is $0.6,0.8,0.6,0.5$, and $0.4 \mathrm{~m}$, and the diameter is $0.02 \mathrm{~m}$. The roots of Magnolia multiflora are in close contact with soil, and there are two main ways of interaction between them: the first is the adhesion between the soil and the organic colloid, and the other is the friction caused by the root system being squeezed by the soil. The adhesion effect is relatively weak. To simplify the simulation, it will not be considered for the time being. The friction effect is similar to that of reinforced soil, which can be embodied by the embedded model in ABAQUS.

The plant-grown slope model is shown in Figure 6. Combined with the results of the indoor test, the soil, the Cynodon dactylon soil composite, and the Magnolia multiflora root system are given the corresponding material properties.

2.4. Boundary Conditions. The boundary conditions of the model are set according to the actual force on the slope. The displacement degrees of freedom in the $X, Y$, and $Z$ directions of the slope bottom are constrained in the initial analysis step. To ensure that the soil can move up and down under gravity or vertical load, the displacements in the $X$ and $Y$ directions of the front, rear, left, and right ends of the slope are constrained.

In addition to displacement constraints, according to the distribution of the groundwater level, one should also set pore pressure boundary conditions. The distribution function is used to set the pore pressure boundary that linearly increases with depth below the water level on both sides of the slope, namely, $10 \times 4-y$. At the same time, the pore pressure of the top surface of the soil layer outside the slope toe is set to 0 , and the remaining boundaries are set as impervious boundaries.

The load boundary condition is mainly composed of two parts: the weight of the material and the rainfall. The selfweight can be defined by setting the density of the soil, rootsoil composite, and deep root system and then adding the vertical downward acceleration of gravity.

The simulation of rainfall is mainly realized by applying vertical loads on the slope. The average rainfall in the test area is used as the rainfall intensity in the previous steadystate analysis, and the calculation result of the subsequent steady-state analysis is used as the initial state of the subsequent transient analysis. The transient analysis is divided into three working conditions: light rain, moderate rain, and heavy rain according to the amount of rainfall. Under the three working conditions, the stability analysis of slopes with and without plants is carried out. The total rainfall duration is 72 hours, the rainfall is shown in Table 5 , and the intensity amplitude variation curve is shown in Figure 7. 


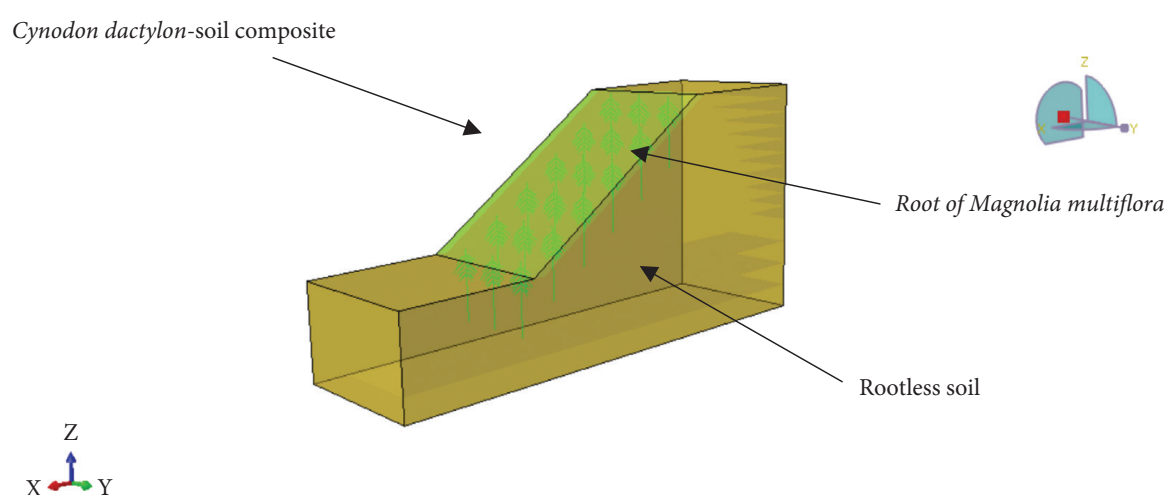

Figure 6: Schematic diagram of the model.

TABLE 5: Daily rainfall grade.

\begin{tabular}{lccc}
\hline Working condition & Light rain & Moderate rain & Heavy rain \\
\hline Daily precipitation $/ \mathrm{mm}$ & $0.8-1.6$ & $1.8-4.4$ & $5.9-10$ \\
\hline
\end{tabular}

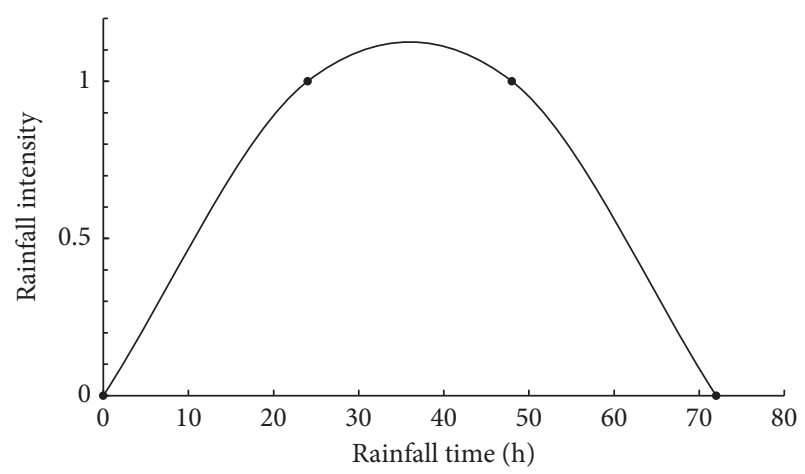

FIGURE 7: Curve of rainfall intensity amplitude.

\section{Results}

3.1. Stress Distribution Characteristics. Taking the slope model after grass and shrub protection under moderate rain conditions as an example, the force of plant roots in the soil is analyzed. Figure 8 is a cloud diagram of the stress distribution of plant roots. Through analysis, it is found that the stress on the root system is mainly concentrated on the main root in the vertical direction, and the magnitude of the stress increases downward along the root system. In addition, the lateral roots distributed around also bear part of the stress, which is mainly manifested as a positive $X$ root system $>$ a negative $X$ root system $>$ a $Y$ direction distributed root system. Figure 9 is a cloud diagram of the plastic strain of the slope after grass and shrub protection. It describes the change in plastic strain in the process of soil deformation and reflects the process of slope instability. It can be seen from the figure that the root system at the toe of the slope passes through the sliding surface, and the root system anchors the shallow soil and the deep soil, which makes a significant contribution to the improvement of the slope stability.

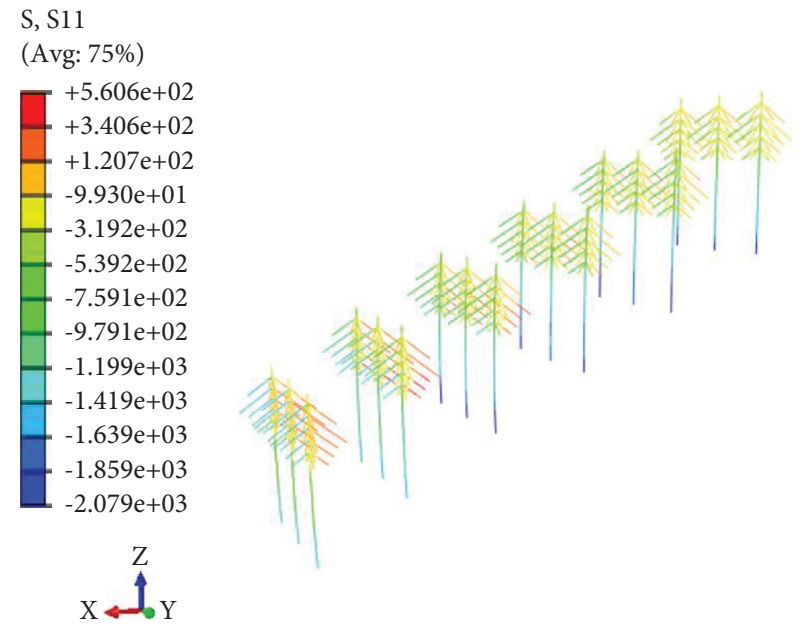

FIGURE 8: Stress distribution cloud diagram of the root of Magnolia multiflora.

3.2. Displacement and Plastic Zone Distribution Characteristics. Sudden changes in displacement are one of the indicators for judging slope failure. In engineering, slope displacement is often used to observe the working status of the slope [34]. When a landslide occurs, a circular arc-shaped sliding surface is usually formed between the landslide body and the parent body [35]. Feature points are uniformly selected along the slope from the center of the slope toe to the center of the top of the slope, and the horizontal and vertical displacements of each point at each time under moderate rain conditions are recorded, as shown in Figures 10 and 11.

The analysis found that $t=0 \mathrm{~h}$ to $t=10 \mathrm{~h}$ is the initial stage, and the soil is stable under its own weight and pore water pressure. At this time, both the horizontal displacement (U1) and the vertical displacement (U3) of the slope surface are small. After rain begins, rainwater infiltrates, and the soil swells slightly. With the increase in rainfall, the 


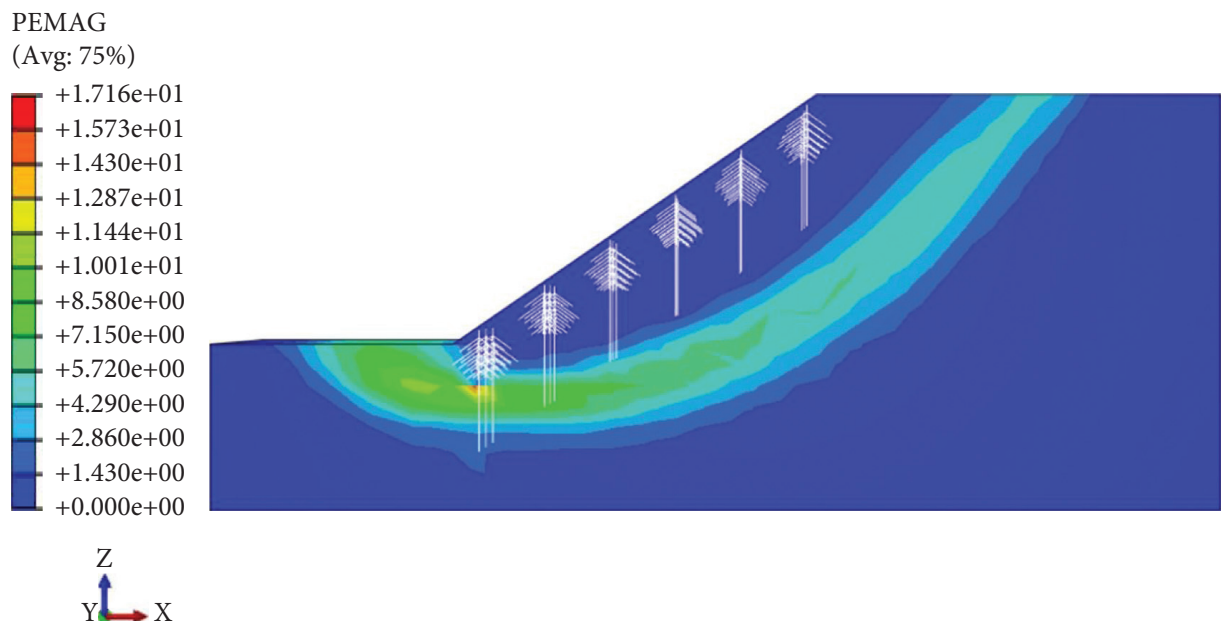

Figure 9: Cloud map of the distribution of the plastic strain area of the slope.
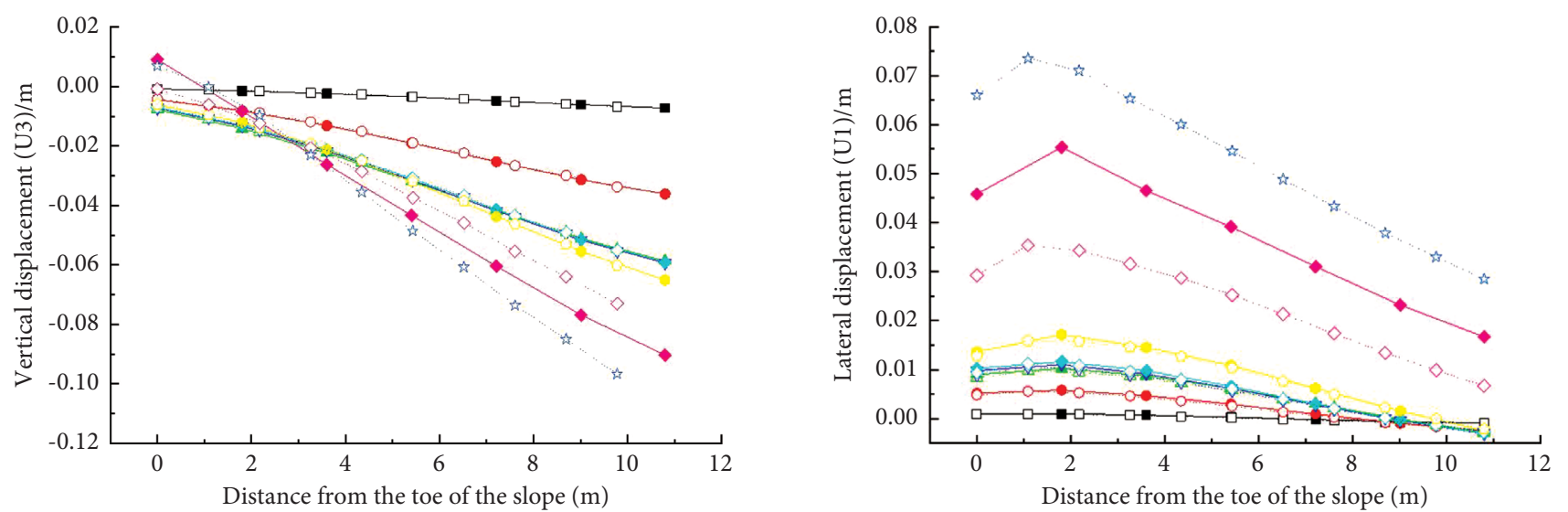

\begin{tabular}{|c|c|}
\hline \multicolumn{2}{|c|}{ No protection } \\
\hline-1 & $\dashv 82$ \\
\hline$\multimap 5.7$ & -82.5 \\
\hline-10 & $\neg 82.6$ \\
\hline \multicolumn{2}{|l|}{$\rightarrow 44.5$} \\
\hline \multicolumn{2}{|c|}{ Plant protection } \\
\hline . ロ . 1 & $\therefore \Delta .82$ \\
\hline .... 5.7 & 82.57 \\
\hline$\cdot \Delta \cdots 10$ & $\therefore \diamond .82 .6$ \\
\hline$\cdot \nabla \cdot . \quad 41.1$ & . \\
\hline
\end{tabular}

FIGURE 10: Vertical displacement of each characteristic point of the downhill foot at each time.

lateral displacement at the bottom of the slope and the vertical displacement at the top of the slope gradually develop. At $t=82 \mathrm{~h}$, the rainfall ends, and the slope settles slightly under the action of rain and appears to slide forward. The cohesive force and internal friction angle of the soil are reduced, and the stability of the slope after infiltration is analyzed by the strength reduction method. From $t=82.5 \mathrm{~h}$ to $t=82.6 \mathrm{~h}$, the vertical displacement (U3) gradually reaches the extreme value at the toe and top of the slope, and the horizontal displacement (U1) reaches the extreme value at a distance of 1 to $2 \mathrm{~m}$ from the toe. Subsequently, the displacement occurs abruptly, and the slope becomes unstable.

FIGURE 11: Lateral displacement of each characteristic point of the downslope foot at each time.

In Figures 10 and 11, the solid line is the displacement change curve without protection, and the dashed line is the displacement change curve after grass and shrub protection. Obviously, it can be observed that the root system of the plant has a better protective effect on the soil. When $t=82.6 \mathrm{~h}$, compared with no protection, the maximum horizontal displacement of the soil body after protection is reduced by $35.4 \%$, and the maximum vertical displacement and maximum negative displacement are reduced by $100 \%$ and $11 \%$, respectively. At the same time, the protected slope is still in a relatively stable state at $t=82.7 \mathrm{~h}$, and at this time, the unprotected slope has already suffered instability damage. 


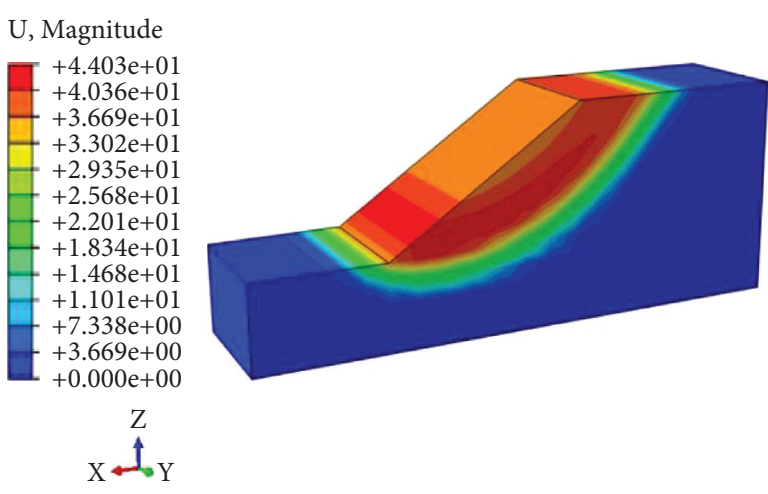

(a)

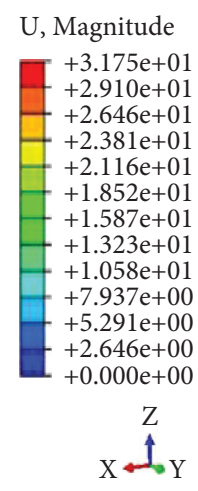

$\mathrm{I}$

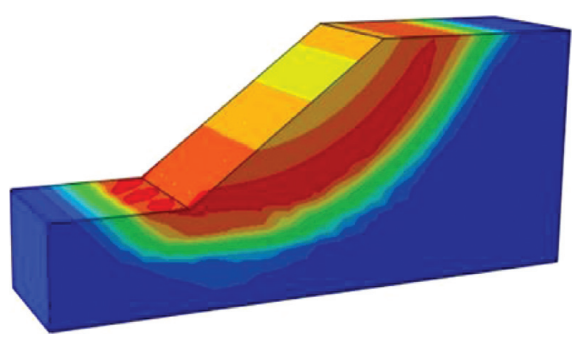

(b)

Figure 12: Slope displacement cloud map. (a) Before slope protection; (b) after planting plants.

PEEQ

(Avg: $75 \%$ )

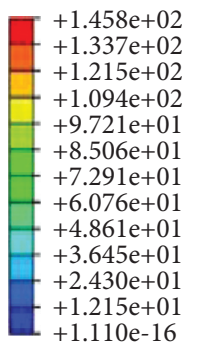

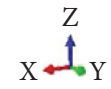

PEEQ

(Avg: 75\%)
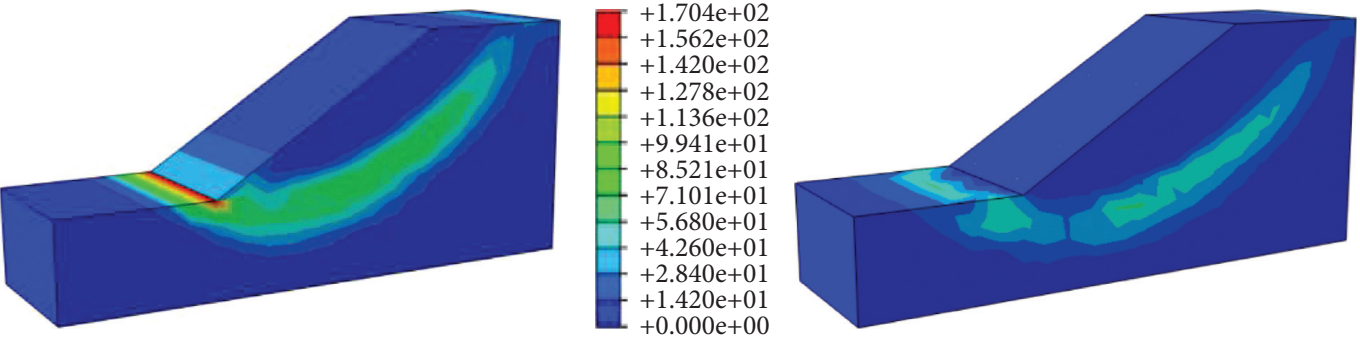

$\mathrm{X}$

(a)

(b)

FIGURE 13: Equivalent plastic stress cloud diagram when an unprotected slope fails. (a) Before slope protection; (b) after planting plants.

Figure 12 is a cloud diagram of the slope displacement. Comparative analysis shows that the overall displacement of the slope has been effectively reduced after the plant root system is used for protection. Soil protection by plant roots on the slope is mainly reflected in two aspects: (1) after grass and shrub protection, the maximum displacement of shallow soil is reduced by $30 \%$; (2) the plant root system connects and anchors the soil as a whole, and its displacement mutation position expands to the rear.

Figure 13 is the equivalent stress cloud diagram after the plastic zone of the slope is completely penetrated. The analysis found that the maximum equivalent plastic stress of an unprotected slope appeared at the foot of the slope, reaching $145 \mathrm{kPa}$. After grass and shrub protection, the slope was connected by the reinforcement effect of shallow roots and the anchoring effect of deep roots, the plastic stress distribution in the slope was more uniform, and the maximum plastic stress value was reduced to $56 \mathrm{kPa}$. While the plant root system delays the plastic strain area through the slope, it also reduces the maximum equivalent plastic stress generated inside the slope.
3.3. Stability Analysis. The center of the slope bottom is selected as a feature point, ABAQUS finite element software is used to draw the relationship curve between the reduction factor $\left(F_{\mathrm{s}}\right)$ and the lateral displacement (U1), the size of the safety factor under each working condition of the slope is obtained by observing the inflection point of the curve, and the result is shown in Figure 14. The analysis found that when there is no protection, the safety factor of light rain to moderate rain is reduced by $4 \%$, and the safety factor of heavy rain to moderate rain is reduced by $9.03 \%$. As the rainfall intensity increases, the safety factor of the slope decreases and the stability decreases, and its downward trend gradually increases. After the protection of herbaceous plants, the permeability coefficient of the root-soil composite is greater than that of the soil, the rainwater penetrates into the deep soil faster, and the slope reaches saturation faster. At this time, the reinforcement effect of the shallow root system is reflected, and the safety factor of the slope is improved to a certain extent. The increase in the safety factor of herbaceous plants to the soil under the three rainfall intensities of small, medium and large is $1.33 \%, 2.08 \%$ and $6.1 \%$, 


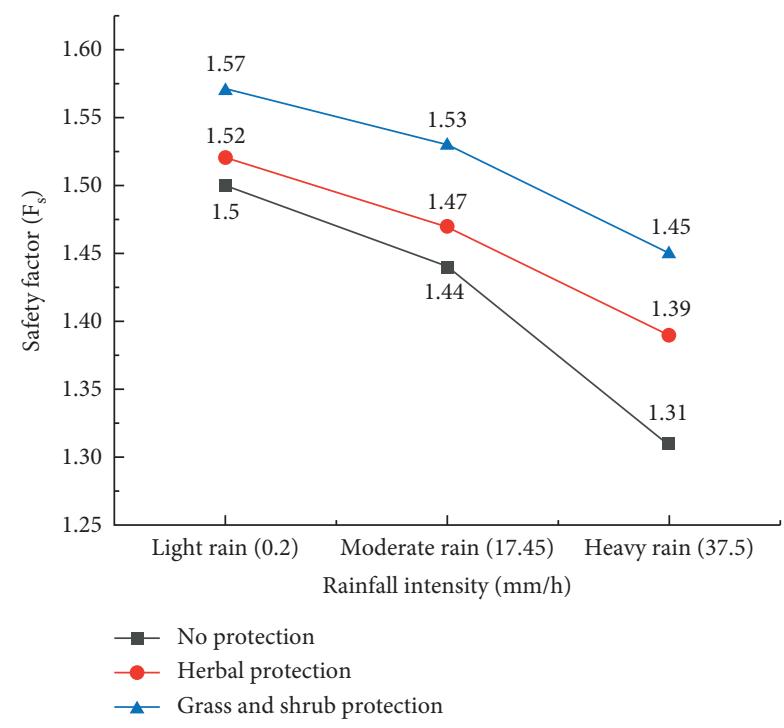

FIGURE 14: Curve of the relationship between rainfall intensity and safety factor.

respectively, and the reinforcement effect is on the rise. After shrub root protection, compared with herb protection, the safety factor of the soil is increased by $3.29 \%, 4.08 \%$, and $4.32 \%$ under the three rainfall intensities of small, medium, and large, respectively. The slope stability is further improved, and since deep roots are mainly anchored, the enhancement effect is relatively stable. Based on the previously mentioned analysis, after mixing grass and shrubs, as the rainfall intensity increases, the effect of plant roots on soil stability is expected to remain stable after reaching the peak.

Under normal circumstances, as the rainfall time increases, rainwater infiltrates gradually, the pore water pressure of the soil increases, the water content increases, and the safety factor of the slope decreases. Taking moderate rain conditions as an example, the stability analysis of slopes after $0 \mathrm{~h}, 12 \mathrm{~h}, 24 \mathrm{~h}, 36 \mathrm{~h}, 48 \mathrm{~h}, 60 \mathrm{~h}$, and $72 \mathrm{~h}$ of rainfall is carried out, and the relationship between the strength reduction coefficient and the lateral displacement is drawn, respectively. The relationship curve between the strength reduction factor and the lateral displacement is drawn separately, and the corresponding safety factor is determined by observing the sudden change of displacement. The collated data are drawn in Figure 15. The analysis shows that, with increasing rainfall time, the stability of the slope first decreases sharply, then decreases slowly, and finally stabilizes. Compared with the bare slope, the safety factor of the vegetation slope is larger, and the root system has a better reinforcement effect on the soil. The analysis shows that because the permeability coefficient of the root-soil composite is greater than that of the rootless soil, rainwater on the planted slope will seep more quickly, which has a certain negative impact on the stability of the slope. But as the soil gradually becomes saturated, this effect gradually decreases, and the reinforcement effect of herb roots and the anchoring effect of shrub roots begin to dominate. Therefore, as the rainfall time increases, the protection effect of plant roots on slopes is better.

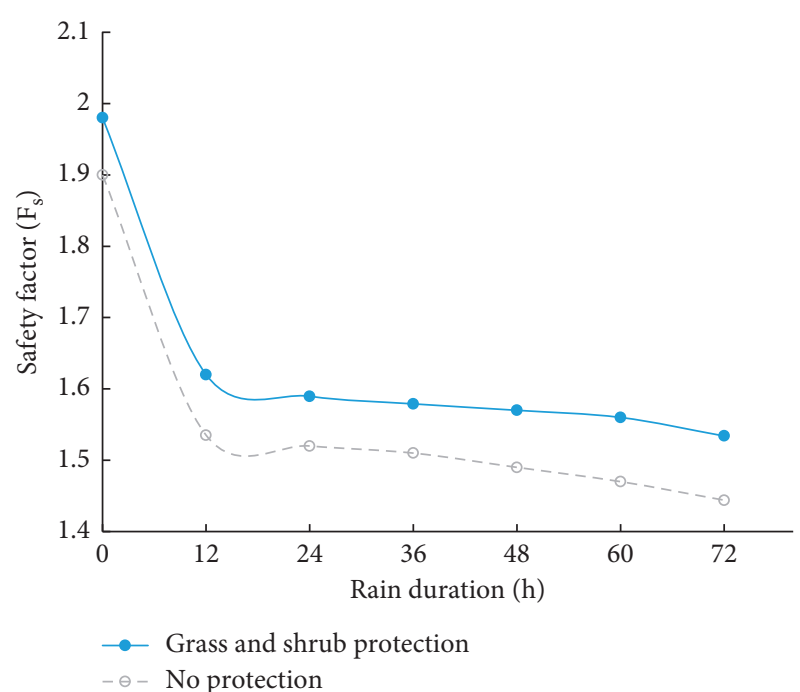

Figure 15: Curve of the relationship between rainfall time and safety factor.

\section{Conclusions}

This study conducted a finite element simulation of the direct shear test of the root-soil composite. This paper uses ABAQUS finite element software to carry out a numerical simulation study on the soil, herb roots, and shrub roots on ecological slopes. According to the actual project, the material properties are assigned, and the boundary conditions are defined. Later, the strength reduction method is used to analyze the stability of the planted slope. By observing the changes in the stress, plastic strain area on the slope, and the safety factor of the characteristic points at the slope toe under different rainfall conditions, the protective effect of the plant root system is explored. The main conclusions are as follows.

(1) The root system of herbaceous plants has a high root content and is mainly distributed in shallow soil, and it has a reinforcing effect on the soil. According to the theory of composite materials, the combination of the soil and root system can be regarded as a composite material. Parameters such as cohesion, internal friction angle, and permeability coefficient are measured through experiments, and the model is constructed with the same type of elements as the soil. Shrubs have a low root content, but the root system is deeply rooted below the sliding surface to anchor the slope. It can be regarded as an anchor material. The model is constructed by using rod elements embedded in the slope soil.

(2) With the increase in rainfall time and rainfall intensity, the water content of the soil increases, the pore water pressure increases, the matrix suction decreases, the safety factor of the slope will gradually decrease, and the slope will lose stability. As a reinforcing material, plant roots can effectively improve the stability of slopes. When the total rainfall duration is constant, the effect of plant roots on the 
slope safety factor increases with the increase in rainfall. When the rainfall intensity is constant, as the rainfall time increases, the safety factor of the slope after plant root protection gradually increases first and finally stabilizes.

(3) The stress borne by plant roots is mainly concentrated on the main root in the vertical direction, and the stress increases downward along the root system. The lateral roots distributed around will also bear part of the stress, and the lateral roots bear greater stress along the slope. It is precisely because the root system shares part of the soil stress that the time for the appearance, development, and penetration of the slope plastic zone is delayed, and the maximum lateral and vertical displacements when the slope soil is damaged are reduced. Plant roots anchor the soil as a whole, and the slope soil can withstand greater stress.

\section{Data Availability}

The data used to support the findings of this study are included within the article.

\section{Conflicts of Interest}

The authors declare that there are no conflicts of interest regarding the publication of this paper.

\section{Acknowledgments}

This research was funded by the Introduction of Key Technologies for Landscape Restoration of Deep Cut Slopes (grant no. 2015-4-38) and Research on Key Technology of Ecological Landscape Restoration of Highway Slope Road in Ecological Fragile Area (grant no. 201803).

\section{References}

[1] H. Zhu and L. M. Zhang, "Field investigation of erosion resistance of common grass species for soil bioengineering in Hong Kong," Acta Geotechnica, vol. 11, no. 5, pp. 1047-1059, 2016.

[2] D. Pimentel, "Soil erosion: a food and environmental threat," Environment, Development and Sustainability, vol. 8, no. 1, pp. 119-137, 2006.

[3] D. R. Montgomery, "Soil erosion and agricultural sustainability," Proceedings of the National Academy of Sciences, vol. 104, no. 33, pp. 13268-13272, 2007.

[4] H. Zhu, L. M. Zhang, T. Xiao, and X. Y. Li, "Enhancement of slope stability by vegetation considering uncertainties in root distribution," Computers and Geotechnics, vol. 85, pp. 84-89, 2017.

[5] P. Reichenbach, C. Busca, A. C. Mondini, and M. Rossi, "The influence of land use change on landslide susceptibility zonation: the Briga catchment test site (Messina, Italy)," Environmental Management, vol. 54, no. 6, pp. 1372-1384, 2014.

[6] J. J. Roering, K. M. Schmidt, J. D. Stock, W. E. Dietrich, and D. R. Montgomery, "Shallow landsliding, root reinforcement, and the spatial distribution of trees in the Oregon Coast
Range," Canadian Geotechnical Journal, vol. 40, no. 2, pp. 237-253, 2003.

[7] B. Indraratna, B. Fatahi, and H. Khabbaz, "Numerical analysis of matric suction effects of tree roots," Proceedings of the Institution of Civil Engineers - Geotechnical Engineering, vol. 159, no. 2, pp. 77-90, 2006.

[8] G. B. Crosta and P. Frattini, "Rainfall-induced landslides and debris flows," Hydrological Processes, vol. 22, no. 4, pp. 473-477, 2008.

[9] F. Tan, W.-H. Zhou, and K. V. Yuen, "Modeling the soil water retention properties of same-textured soils with different initial void ratios," Journal of Hydrology, vol. 542, pp. 731-743, 2016.

[10] W. Wu, B. M. Switala, M. S. Acharya et al., "Effect of vegetation on stability of soil slopes: numerical aspect," Springer Series in Geomechanics and Geoengineering, Springer, Berlin, Germany, pp. 163-177, 2015.

[11] C. O'Loughlin, “The effect of timber removal on the stability of forest soils," Journal of Hydrology (New Zealand), vol. 13, no. 2, pp. 121-134, 1974.

[12] N. P. Bankhead and A. Simon, "Hydrologic and hydraulic effects of riparian root networks on streambank stability: is mechanical root-reinforcement the whole story?" Geomorphology, vol. 116, no. 3-4, pp. 353-362, 2010.

[13] E. B. Masi, S. Segoni, and V. Tofani, "Root reinforcement in slope stability models: a review," Geosciences, vol. 11 , no. 5, p. 212, 2021.

[14] M. Schwarz, A. Rist, D. Cohen et al., "Root reinforcement of soils under compression," Journal of Geophysical Research: Earth Surface, vol. 120, no. 10, pp. 2103-2120, 2015.

[15] W. H. Zhou and X.-H. Qi, "Root cohesion estimation of riparian trees based on model uncertainty characterization," Journal of Materials in Civil Engineering, vol. 31, no. 2, Article ID 04018389, 2019.

[16] M. Pallewattha, B. Indraratna, A. Heitor, and C. Rujikiatkamjorn, "Shear strength of a vegetated soil incorporating both root reinforcement and suction," Transportation Geotechnics, vol. 18, pp. 72-82, 2019.

[17] T. C. Hales and C. F. Miniat, "Soil moisture causes dynamic adjustments to root reinforcement that reduce slope stability," Earth Surface Processes and Landforms, vol. 42, no. 5, pp. 803-813, 2017.

[18] T. H. Wu, Investigation of Landslides on Prince of Wales Island Alaska, Ohio State University, Columbus OH U S A, 1976.

[19] L. J. Waldron, "The shear resistance of root-permeated homogeneous and stratified soil," Soil Science Society of America Journal, vol. 41, no. 5, pp. 843-849, 1977.

[20] N. Pollen and A. Simon, "Estimating the mechanical effects of riparian vegetation on stream bank stability using a fiber bundle model," Water Resources Research, vol. 41, no. 7, 2005.

[21] D. Cohen, M. Schwarz, and D. Or, "An analytical fiber bundle model for pullout mechanics of root bundles," Journal of Geophysical Research: Earth Surface, vol. 116, no. F3, 2011.

[22] J. C. Bathurst, C. I. Bovolo, and F. Cisneros, "Modelling the effect of forest cover on shallow landslides at the river basin scale," Ecological Engineering, vol. 36, no. 3, pp. 317-327, 2010.

[23] M. Xie, T. Esaki, G. Zhou, and Y. Mitani, "Geographic information systems-based three-dimensional critical slope stability analysis and landslide hazard assessment," Journal of Geotechnical and Geoenvironmental Engineering, vol. 129, no. 12, pp. 1109-1118, 2003.

[24] D. V. Griffiths and P. A. Lane, "Slope stability analysis by finite elements,” Géotechnique, vol. 49, no. 3, pp. 387-403, 1999. 
[25] V. J. Terwilliger and L. J. Waldron, "Effects of root reinforcement on soil-slip patterns in the Transverse Ranges of southern California," The Geological Society of America Bulletin, vol. 103, no. 6, pp. 775-785, 1991.

[26] Z. F. Sui, W. Yi, Y. G. Lu, and L. Deng, "Experimental and numerical simulation study on the shear strength characteristics of magnolia multiflora root-soil composites," $A d$ vances in Civil Engineering, vol. 2021, Article ID 6642594, 12 pages, 2021.

[27] A. G. T. Temgoua, N. K. Kokutse, and Z. Kavazović, "Influence of forest stands and root morphologies on hillslope stability," Ecological Engineering, vol. 95, pp. 622-634, 2016.

[28] N. K. Kokutse, A. G. T. Temgoua, and Z. Kavazović, "Slope stability and vegetation: conceptual and numerical investigation of mechanical effects," Ecological Engineering, vol. 86, pp. 146-153, 2016.

[29] Y. H. Chok, M. B. Jaksa, W. S. Kaggwa, and D. V. Griffiths, "Assessing the influence of root reinforcement on slope stability by finite elements," International Journal of GeoEngineering, vol. 6, no. 1, pp. 1-13, 2015.

[30] E. M. Schmaltz and M. Mergili, "Integration of root systems into a GIS-based slip surface model: computational experiments in a generic hillslope environment," Landslides, vol. 15, no. 8, pp. 1561-1575, 2018.

[31] F. Giadrossich, M. Schwarz, D. Cohen et al., "Methods to measure the mechanical behaviour of tree roots: a review," Ecological Engineering, vol. 109, pp. 256-271, 2017.

[32] P. P. Capilleri, M. Cuomo, E. Motta, and M. Todaro, "Experimental investigation of root tensile strength for slope stabilization," Indian Geotechnical Journal, vol. 49, no. 6, pp. 687-697, 2019.

[33] E. M. Schmaltz, L. P. H. Van Beek, T. A. Bogaard, S. Kraushaar, S. Steger, and T. Glade, "Strategies to improve the explanatory power of a dynamic slope stability model by enhancing land cover parameterisation and model complexity," Earth Surface Processes and Landforms, vol. 44, no. 6, pp. 1259-1273, 2019.

[34] H. Wang, Y. He, Z. Shang, C. Han, and Y. Wang, "Model test of the reinforcement of surface soil by plant roots under the influence of precipitation," Advances in Materials Science and Engineering, vol. 2018, Article ID 3625053, 2018.

[35] X. Wang, M. M. Hong, Z. Huang et al., "Biomechanical properties of plant root systems and their ability to stabilize slopes in geohazard-prone regions," Soil and Tillage Research, vol. 189, pp. 148-157, 2019. 